\title{
An Innocent Horn: A Case Report of Giant Cutaneous Horn
}

\author{
Lina Liana Ahmad Adni ${ }^{1}$, Mohd Noor Norhayati ${ }^{{ }^{*}}$, Juliawati Muhammad ${ }^{1}$, Azuhairy Azid ${ }^{2}$, \\ Nik Abdul Muhaimin Nik Ramli ${ }^{3}$
}

\author{
${ }^{1}$ Department of Family Medicine, School of Medical Sciences, Health Campus, Universiti Sains Malaysia, Kubang Kerian, Kelantan, MALAYSIA \\ ${ }^{2}$ Department of Orthopaedics, Hospital Pulau Pinang, Georgetown, Penang, MALAYSIA \\ ${ }^{3}$ Department of Orthopaedics, Hospital Sultan Abdul Halim, Sungai Petani, Kedah, MALAYSIA \\ `Corresponding Author: hayatikk@usm.my
}

Citation: Ahmad Adni LL, Norhayati MN, Muhammad J, Azid A, Nik Ramli NAM. An Innocent Horn: A Case Report of Giant Cutaneous Horn. Electron J Gen Med. 2022;19(1):em343. https://doi.org/10.29333/ejgm/11414

ARTICLE INFO

Received: 13 Sep. 2021

Accepted: 13 Nov. 2021

\begin{abstract}
Background: Cutaneous horns are not malignant per se. It is a rare, dark keratinized protrusion on the surface of the skin. The incidence and prevalence in general population is unknown. However, most cases occur in elderly aged 60 years and older.

Case Report: We reported an interesting case of an 80-year-old man who developed a giant cutaneous horn on a forearm which was gradually increasing in size over seven years. He was referred to our primary care clinic by a doctor who is involved in humanitarian mission in an old folk's home who noticed a hornlike projection growth over his forearm. He was then referred to orthopedic department and underwent an excisional biopsy with adequate margin. Histology findings reported as prominent epithelial hyperplasia marked by hyperkeratosis and papillomatosis which indicates the lesion is caused by verruca vulgaris or a common wart. Such warts are usually benign which is caused by subtypes of human papilloma virus that are not associated with malignant transformatio $\mathrm{n}$.

Conclusions: This is a rare case of giant cutaneous horn located on forearm of an elderly man. It's highlighted that giant cutaneous horn is not always associated with malignancy especially when they are slow growing over a period of time. It also highlights the role of biopsies for skin lesions of uncertain aetiologies. In this case, it helped us to rule out squamous cell carcinoma, which can be a more locally invasive and destructive. Hence, early referral for excisional biosy and histopathological studies is mandatory for all cases.
\end{abstract}

Keywords: cutaneous horn, cornu cutaneum, squamous cell carcinoma, verruca vulgaris, human papilloma virus

\section{INTRODUCTION}

Cutaneous horn is a common entity in Caucasian and western region. However, there is limited case reported from Asian or southeast region. Giant cutaneous horns are even more rare and are commonly associated with malignant pathology such as squamous cell carcinoma. The present case is one of the biggest cutaneous horns at the forearm recorded in literature. This case reflects lack of health seeking behaviour and personal neglect by the patient as he is staying in the old folk's home. We report here on a case of a giant cutaneous horn originating from verruca vulgaris in an 80-year-old Malaysian gentleman.

\section{CASE REPORT}

An 80-year-old gentleman presented in my primary care clinic after been referred by a doctor who visiting his old folk's home on a humanitarian mission with a slow progressing growth on his right forearm for seven years. He has been staying in the old folk's home for the past 5 years and never seeks treatment for that matters. The lesion was occasionally painful, but he denied any history of bleeding or discharges. The lesion appeared spontaneously seven years ago. He reports, initially it was only a small growth and gradually increasing in size. He denied any skin lesion prior, trauma or burn injuries. There is no other lesion elsewhere on the body. $\mathrm{He}$ has no other medical condition and was not on any medication. He has history of smoking for the past 30 years. He did not take any alcohol or recreational drugs. His family history was unremarkable.

On examination, patient appear comfortable and not in distress. His blood pressure was $138 / 75 \mathrm{mmHg}$ and pulse rate was 87 per minute, while his body mass index was $21 \mathrm{~kg} / \mathrm{m}^{2}$. Examination of his cardiovascular and respiratory system were unremarkable. There was no regional lymphadenopathy. On examination of his right forearm, there is a hard and hornlike projection from the skin, with blackish grey in color, curved keratinized lesion measuring $6.5 \mathrm{~cm} \times 5 \mathrm{~cm} \times 10 \mathrm{~cm}$ on the posteromedial aspect of his right forearm. The base of the horn showed some inflammation and redness, but no contact bleeding seen (See Figures $\mathbf{1} \mathbf{a}$ and $\mathbf{1} \mathbf{b}$ ).

The lesions were diagnosed clinically as cutaneous horn. In view of the huge size of the lesions and his age, he was referred to orthopedic team for further assessment and management. He was initially reluctant for surgical intervention but finally 

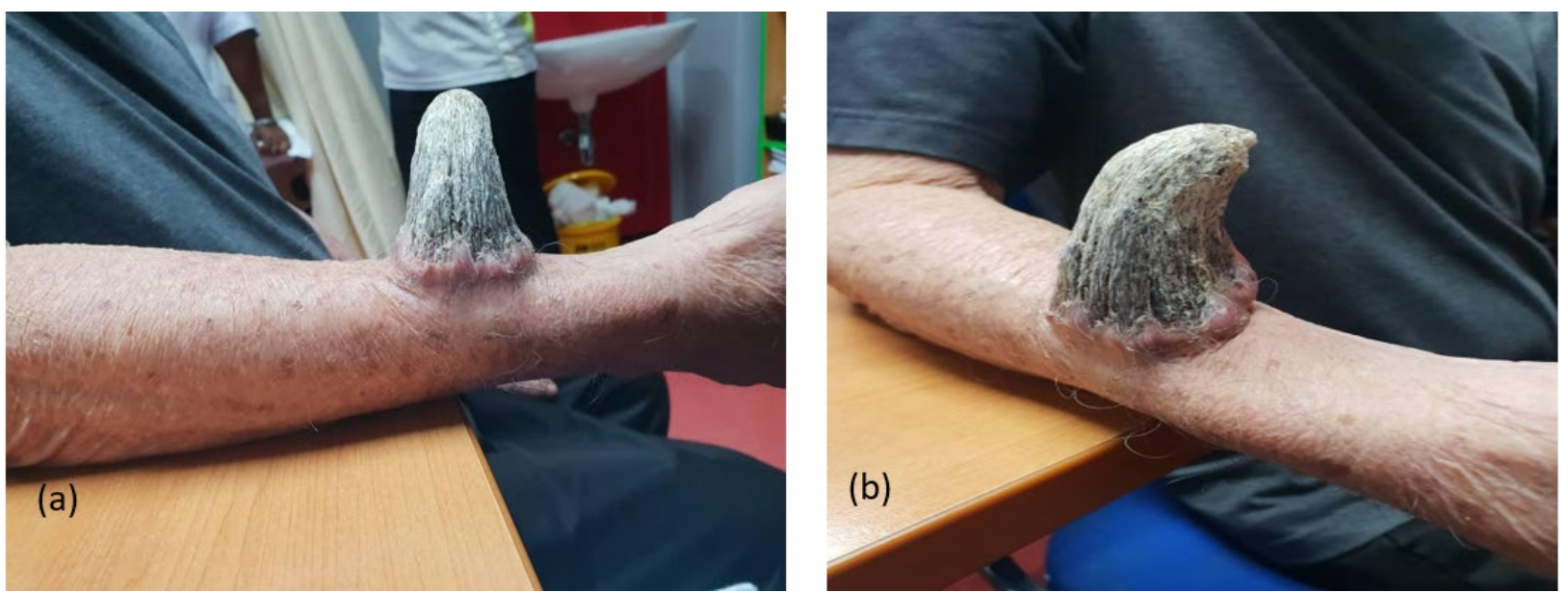

Figure 1. (a) Cutaneous horn (lateral view) with a crateriform shape base at the forearm and surrounded with granulation (b) Cutaneous horn (frontal view) at the forearm
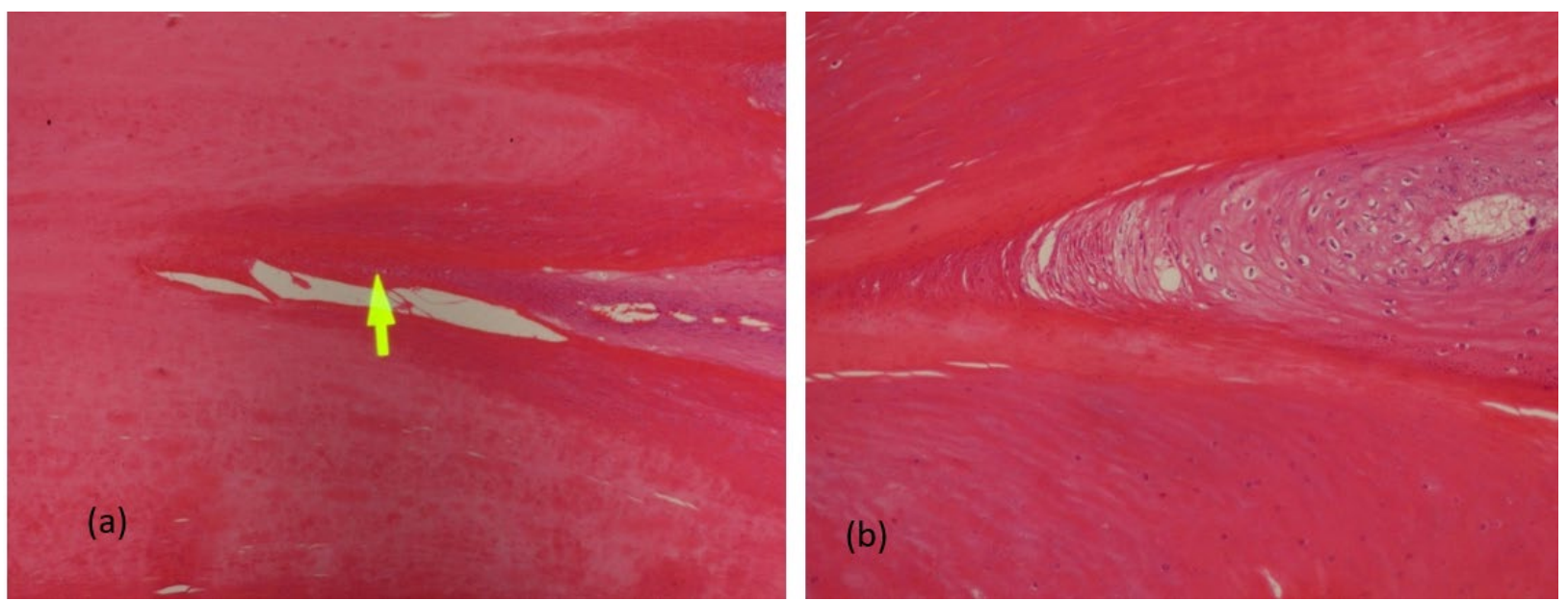

Figure 2. (a) Photomicrograph of the edge of the lesions showing acanthotic and papillomatosis epidermis with marked hyperkeratosis depicted by the arrow at $4 \times 100$ magnification (b) Photomicrograph at $4 \times 10$ magnification showing top of an epidermal papilloma assuming of a church spire shape. Noted marked koilocytosis at the right with tiers of parakeratosis at the left

agreed after a lengthy discussion. He subsequently underwent full thickness excisional biopsy with an adequate margin. This is crucial and paramount to rule out underlying malignancy lesion.

Macroscopically, the specimen was reported as a mass measuring $6.5 \mathrm{~cm} \times 4.5 \mathrm{~cm} \times 12 \mathrm{~cm}$. The consistency is firm to hard with a homogenous appearance and no area of necrosis. Microscopically, it revealed a papillomatous epidermal lesion with marked hyperkeratosis and tiers of parakeratosis. These features were consistent with verruca vulgaris. There was no evidence of malignancy seen (See Figures $\mathbf{2} \mathbf{a}$ and $\mathbf{2 b}$ ). The patient was kept in the ward post operation and discharged few days afterward with no complication. On subsequent clinic visit the wound healed well and no recurrence of the mass noted after six months of follow-up. As of this writing, he is in good physical health without recurrence.

\section{DISCUSSION}

A cutaneous horn is rare and uncommon lesions. The true incidence and prevalence rates of cutaneous horns are not documented in the literature [1]. Giant cutaneous horn does exist. The largest giant cutaneous horn described is a case of Mexican man named Paul Rodrigues, in the 18th century who had enormous horny growth emerging from right side of on his head about $35 \mathrm{~cm}$ long [2]. The present case is the largest cutaneous horn on the forearm that is ever documented in literature.

A cutaneous horn is a clinical entity having the appearance of an animal horn of various shapes and length. Although grossly it looks like horns in animals, they are histologically quite different. An animal horns usually contain an osseous cast but in cutaneous horns it consists solely of cornified proliferative keratinocytes. The base of the horn maybe flat, nodular or crateriform $[3,4]$. Clinically, cutaneous horns vary in size from a few millimeters to several centimeters. The horn maybe white, black, or yellowish in color and it may be straight, curved or twisted so clinical suspicion should be confirmed by histopathological analysis [4,5].

A cutaneous horn is more common in elderly population, with the peak incidence in those between 60 to 80 years of age. They are equally common in males and females, although there is a higher risk of the lesion being malignant in men [6]. They are also more likely to be premalignant or malignant in geriatric populations and people with a fairer skin $[7,8]$. 
Cutaneous horn usually arises in areas exposed to the sun but can also arise in sun-protected areas. The most common sites are on the head, ears, back of hands and forearms [6,7]. There are some reported cases which arise from areas not exposed to sunlight such as the chest, shoulder and penis $[9,10]$.

A retrospective study of 643 cases of cutaneous horn by $\mathrm{Yu}$ et al in 1991 revealed that around half of cutaneous horns have a benign base, and half are premalignant or malignant [7]. The most common benign cause of cutaneous horns is seborrheic keratoses, molluscum contagiosum, hypertrophic lichen planus or verruca vulgaris. As in our case the cause of the horn is by verruca vulgaris. Actinic keratoses and keratoacanthoma are the most common premalignant cause of cutaneous horn. While squamous cell carcinoma is the most common malignant cause. There are no certain features can confirm malignant lesions, but squamous cell carcinoma is likely if the horn is large and if there is presence of induration [11] and redness at the base such as in this case $[6,12]$.

The current standard of care for cutaneous horns is complete excisional biopsy [6,13]. A full thickness excisional biopsy with an adequate margin should be performed and followed by histopathological assessment $[14,15]$. There are few non-invasive treatments available including cryosurgery, laser ablation or electrocautery. However, it is not recommended because it does not preserve histopathology specimen and these methods are likely to be used in cases with low malignancy risk and small size lesions $[8,11]$. As in our presented case, the dimension of the cutaneous horn is relatively huge with additional risk factor, elderly man with fair skinned and inflamed base, there was a high degree of suspicion of malignancy and hence those methods are not applicable. Thus, complete surgical excision with clear margins was adopted as the treatment of choice. Although giant cutaneous horn is more common with malignant pathology, a few cases has been reported with benign histopathological findings such as verruca vulgaris [16] as in our cases, burn scar [17], seborrheic keratosis [18] and naevus sebaceous [19].

\section{CONCLUSIONS}

After reviewing in a various literature database, the cutaneous horn presented in this case report is by far the largest cutaneous horn documented in a forearm. It is important to highlight that the most important part is not the horn itself but rather the underlying condition underneath it. It also highlights those giant cutaneous horns may not always be associated with malignancy, especially when they are growing slowly over time.

Author notes: This study was performed at Department of Family Medicine, School of Medical Sciences, Health Campus, Universiti Sains Malaysia, Kubang Kerian, Kelantan, Malaysia. The case report abstract was previously presented as poster at Malaysian Orthopaedic Association (MOA) Annual Scientific Meeting on 2-4 April 2019 and subsequently published in Malaysian Orthopaedic Journal (MOJ) May 2019, Volume 13 , as abstract supplement.

Author contributions: All authors have sufficiently contributed to the study, and agreed with the results and conclusions.

Funding: No funding source is reported for this study.

Acknowledgements: We sincerely thank the patient, who agreed to be described in this case report. We would also like to acknowledge $\mathrm{Dr}$ Othman Abdullah from the Department of Pathology, Hospital Sultan Abdul Halim, Sungai Petani, Kedah for his assistance with the histopathology image.
Declaration of interest: No conflict of interest is declared by authors. Informed Consent Statement: Informed consent was obtained from subject involved in this case report.

\section{REFERENCES}

1. Akram H, Jing SS, Murahari S, David K. Cutaneous horn: case report. Br J of Oral Maxillofac Surg. 2011;49(1):73-5. https://doi.org/10.1016/j.bjoms.2009.09.019 PMid:20226577

2. Bondeson J. Everard Home, John Hunter, and cutaneous horns: a historical review. Am J Dermatopathol. 2001;23(4):362-9. https://doi.org/10.1097/00000372200108000-00014 PMid:11481530

3. Klauss Wolff RAJ, Arturo P. Saavedra. Cutaneous Horn. In: Anne M. Sydor MRE, editor. Fitzpatricks's Color Atlas \& Synopsis of Clinical Dermatology. 7th edition. United States of America: McGraw Hill; 2013. p. 227-8.

4. Michal M, Bisceglia M, Di Mattia A, Requena L, FanburgSmith JC, Mukensnabl P, et al. Gigantic cutaneous horns of the scalp: Lesions with a gross similarity to the horns of animals: A report of four cases. Am J Surg Pathol. 2002;26(6):789-94. https://doi.org/10.1097/00000478200206000-00014 PMid:12023585

5. Kumar S, Bijalwan P, Saini SK. Carcinoma buccal mucosa underlying a giant cutaneous horn: A case report and review of the literature. Case Reports in Oncological Medicine. 2014;2014:518372. https://doi.org/10.1155/ 2014/518372 PMid:25133002 PMCid:PMC4123614

6. Copcu E, Sivrioglu N, Culhaci N. Cutaneous horns: are these lesions as innocent as they seem to be? World J Surg Oncol. 2004;2(1):1-4. https://doi.org/10.1186/1477-7819-2-18 PMid:15176977 PMCid:PMC421749

7. Yu R, Pryce D, Macfarlane A, Stewart T. A histopathological study of 643 cutaneous horns. $\mathrm{Br} J$ Dermatol. 1991;124(5):449-52. https://doi.org/10.1111/j.13652133.1991.tb00624.x PMid:2039721

8. Mantese SA, Diogo PM, Rocha A, Berbert AL, Ferreira AK, Ferreira TC. Cutaneous horn: a retrospective histopathological study of 222 cases. The Brazilian Annals of Dermatology. 2010;85(2):157-63. https://doi.org/10.1590 /s0365-05962010000200005 PMid:20520930

9. Mutaf M. A rare perioral lesion: cutaneous horn of the lower lip. Eur J Plast Surg. 2007;29(7):339-41. https://doi.org/10.1007/s00238-006-0101-y

10. Rekha A, Ravi A. Cornu cutaneum-cutaneous horn on the penis. Indian J Surg. 2004;66(5):296-7.

11. Lowe FC, McCullough AR. Cutaneous horns of the penis: an approach to management. Case report and review of the literature. Journal of the American Academy of Dermatology. 1985;13(2 Pt 2):369-73. https://doi.org/ 10.1016/S0190-9622(85)70177-6

12. Mantese SA, Diogo PM, Rocha A, Berbert AL, Ferreira AK, Ferreira TC. Cutaneous horn: a retrospective histopathological study of 222 cases. Anais Brasileiros de Dermatologia. 2010;85(2):157-63. https://doi.org/10.1590/ s0365-05962010000200005 PMid:20520930

13. Nahhas AF, Scarbrough CA, Trotter S. A Review of the Global Guidelines on Surgical Margins for Nonmelanoma Skin Cancers. J Clin Aesthet Dermatol. 2017;10(4):37-46. PMC: 5404779

14. Thappa DM, Laxmisha C. Cutaneous horn of eyelid. Indian Pediatr. 2004;41(2):195. 
15. Yang JH, Kim DH, Lee JS, Cho MK, Lee SH, Lee SY, et al. A case of cutaneous horn originating from keratoacanthoma. Ann Dermatol. 2011;23(1):89-91. https://doi.org/10.5021/ ad.2011.23.1.89 PMid:21738372 PMCid:PMC3120008

16. Gould J, Brodell R. Giant cutaneous horn associated with verruca vulgaris. Cutis. 1999;64(2):111-2.

17. Nthumba PM. Giant cutaneous horn in an African woman: a case report. J Med Case Rep. 2007;1(1):170. https://doi.org/10.1186/1752-1947-1-170 PMid:18053226 PMCid:PMC2225419
18. Kumaresan M, Kumar P, Pai M. Giant cutaneous horn. Indian J Dermatol. 2008;53(4):199. https://doi.org/10.4103/ 0019-5154.44800 PMid:19882036 PMCid:PMC2763752

19. Arvas L, Livaoglu M, Karacal N, Sozen E, Kara B. Giant cutaneous horn with naevus sebaceus. J Plast Reconstr Aesthet Surg. 2007;60(11):1268-9. https://doi.org/10.1016/ j.bjps.2007.06.015 PMid:17656171 